The empirical study of social norms has been hampered by a lack of standardized quantitalive measures and criteria for the interpretation of research data. Two such criteria we suggested, both of them derived from the modal proportion of responses. The first, pkire, signifies a modal proportion largeenough to represem a population norm. The second criterian, $p k_{1 \text { nromo }}$ is less stringent and indicates the presence of a prominem norm. Minority norms and plurality norms are atso quantiratively defined. THO empirical examples are given to ithistrate the uility of the suggested criturita.

\title{
Interpreting Modal Frequencies To Measure Social Norms
}

\author{
CHANOCH JACOBSEN
}

The Technion, Israel Institute of Technology

\author{
THEO J.M. VAN DER VOORDT \\ Delft University of Technology
}

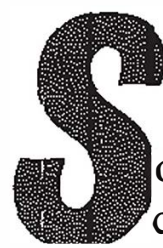

ocial norms have traditionally been among the central concerns of theoretical sociology. Various suggestions have been made over the years to bring order to their variety by developing typologies, taxonomies, and other descriptive systems (Sumner, 1906; Williams, 1951; Morris, 1956; Gibbs, 1965). In the empirical study of normative systems and deviant behavior, however, these insights have not been utilized to the extent one should have expected. This is due, in part, to the unwieldy multidimensionality of the concept, but probably no less to the lack of established quantitative criteria by which norms could be assessed (Gibbs, 1968: 210). An increase in publications about

AUTHORS' NOTE: We wish to thank Michael Jacobsen, Institute of Occupational Medicine, Edinburgh, and Herbert S. Sichel, University of the Witwatersrand, Johannesburg, for their expert advice and criticism. Our colleagues at the Technion, Albert Goldberg, Moshe Pollatschek, Ayala Cohen, Paul Feigin, and Benjamin Reiser, as well as two anonymous reviewers, have read successive drafis of the manuscript and made valuable suggestions for its improvement. Responsibility for the final product rests with the authors. 
these issues (see Labovitz and Hagedorn, 1973; Hawkes, 1975; Hendrix, 1976) suggests that the need for methodological refinement in the study of social norms is becoming more widely felt.

A social norm is "a standard shared by the members of a social group, to which the members are expected to conform" (Kolb, 1964: 472). Although authorities differ as to what else should be included in the definition (see Gibbs, 1965), it seems to be generally accepted that norms "must be shared prescriptions" (Morris, 1956). Thus, the level of agreement about normative statements is a critical part of their definition, and we may take the degree to which people agree about a prescription as a valid indication of the degree to which it is a social norm.

But there are methodological problems. It is easy enough to recognize unanimity and extreme conflict of opinion when one sees them, but the intermediate levels of a greement (or disagreement) with normative statements, or approval (or disapproval) of a given mode of conduct, pose difficulties in measurement as well as interpretation (Williams, 1968: 207-208; Rossi et al., 1974).

Concerning measurement, there are some norms which prescribe an appropriate amount or intensity of behavior in a given situation. For these, the variance of the amount or intensity expected will indicate the level of agreement (for an example, see Turk, 1965). Many social situations, however, are not governed by this type of norm and are therefore not measureable in this manner. Different people may expect categorically different modes of conduct in terms of "either this or that," of dos and don'ts. The variation here is in kind, not in degree. The logically most appropriate measure for ascertaining the existence and status of a social norm in such situations is the relative frequency of the modal response, but for this we have no associated measure of variation.

Problems of interpretation arise in both types of cases. How small must the variance be, or how large must be the relative frequency of the modal response to enable us to say that there is a social norm? Obviously, we cannot speak meaningfully of conformity or deviance in observed behavior unless we have 
independent evidence that there is, indeed, a norm. ${ }^{\prime}$ Objective and standardized criteria are needed for determining the point at which normative statements are accepted by a proportion of a population large enough to constitute a social norm (see Mueller and Schuessler, 1961: 120).

In this article we shall propose a series of criteria to facilitate the sociological interpretation of modal responses. We are well aware, of course, that agreement is a necessary condition not only for the definition of social norms but also for establishing the validity of sociological concepts. Therefore, for all the confidence we have in the sound ness of the proposed criteria, their practical utility will depend very much on the degree to which they are accepted and applied by practicing social scientists.

\section{REPRESENTATIVE NORMS}

To infer the existence of a norm from a modal response, we must look at the proportion of responses (p) in the modal category $\left(\mathrm{k}_{1}\right)$. The normative significance of a modal response varies directly with the proportion of people who made it: The greater the proportion, the more likely it is to represent a social norm. However, the normative significance of a modal proportion also varies inversely with the number of possible response categoriès. A proportion which would clearly signify a norm when there are, say, ten different response categories may be much too low to speak of a norm when there are only two or three such categories. In other words, the fewer response categories there are, the larger must be the proportion of responses in the modal category to signify a norm. Can we establish a standard lower limit for the modal proportion which takes account of this cónstraint? ${ }^{2}$

In mathematical terms, consensus exists when the proportion in the modal category $\left(\mathrm{pk}_{1}\right)$ is unity. Total disagreement is found when $\mathrm{pk}_{1}=\mathrm{pk}_{2}=\mathrm{pk}_{3}=\ldots=\mathrm{pk}_{\mathrm{k}}=1 / \mathrm{K}$ (K denoting the number of response categories). Assuming a linear increasing function of modal proportions from total disagreement $\left(\mathrm{pk}_{1}=1 / \mathrm{K}\right)$ to 
consensus $\left(\mathrm{pk}_{\mathrm{I}}=1.00\right),{ }^{3}$ we can define the proportion which lies exactly midway between consensus and disagreement.

$$
\text { "midway" proportion }=1 / 2(1+1 / K) \text {. }
$$

Any modal proportion greater than expression $\mathbf{I}$ is closer to consensus than to disagreement and therefore implies a tendency toward convergence rather than divergence of opinions, while any proportion smaller than that implies the opposite (Figure 1). Moreover, expression I varies inversely with the number of response categories, its range being $(1 / 2,3 / 4)$. It is, therefore, an accurate reflection of the normative significance of the modal proportion, and establishes an objective standard lower boundary to agreement.

We shall call this boundary $\mathrm{pk}_{1 \text { rep }}$ because when it is found it may safely be said to indicate a representative norm, the relative frequency of the modal category being so great that it represents the population's response for most intents and purposes. For samples, a one-tailed lower confidence limit for the observed proportion can be computed at the desired level of probability (Blalock, 1960: 163-165), giving an estimate with known probability of agreement in the population. ${ }^{4}$

Applying this criterion to various sets of empirical data, however, we have found that it is met only rarely. This is not surprising, really, because researchers are much more likely to study equivocal norms than those which are distinct enough to yield a $\mathrm{pk}_{\text {rep. }}$. For many empirical cases, therefore, we need an additional, less stringent criterion in order to make clear and objective interpretations.

\section{PROMINENT NORMS}

When a modal response does not reach $\mathrm{pk}_{\mathrm{l} \text { rep}}$, its normative connotation depends very heavily on its relative prominence, that is, on the difference between the proportion in the modal category and that in the next most frequent category, $\left(\mathrm{pk}_{1}-\mathrm{pk}_{2}\right)$. Generally speaking, the larger this difference is, the more likely it is that the 


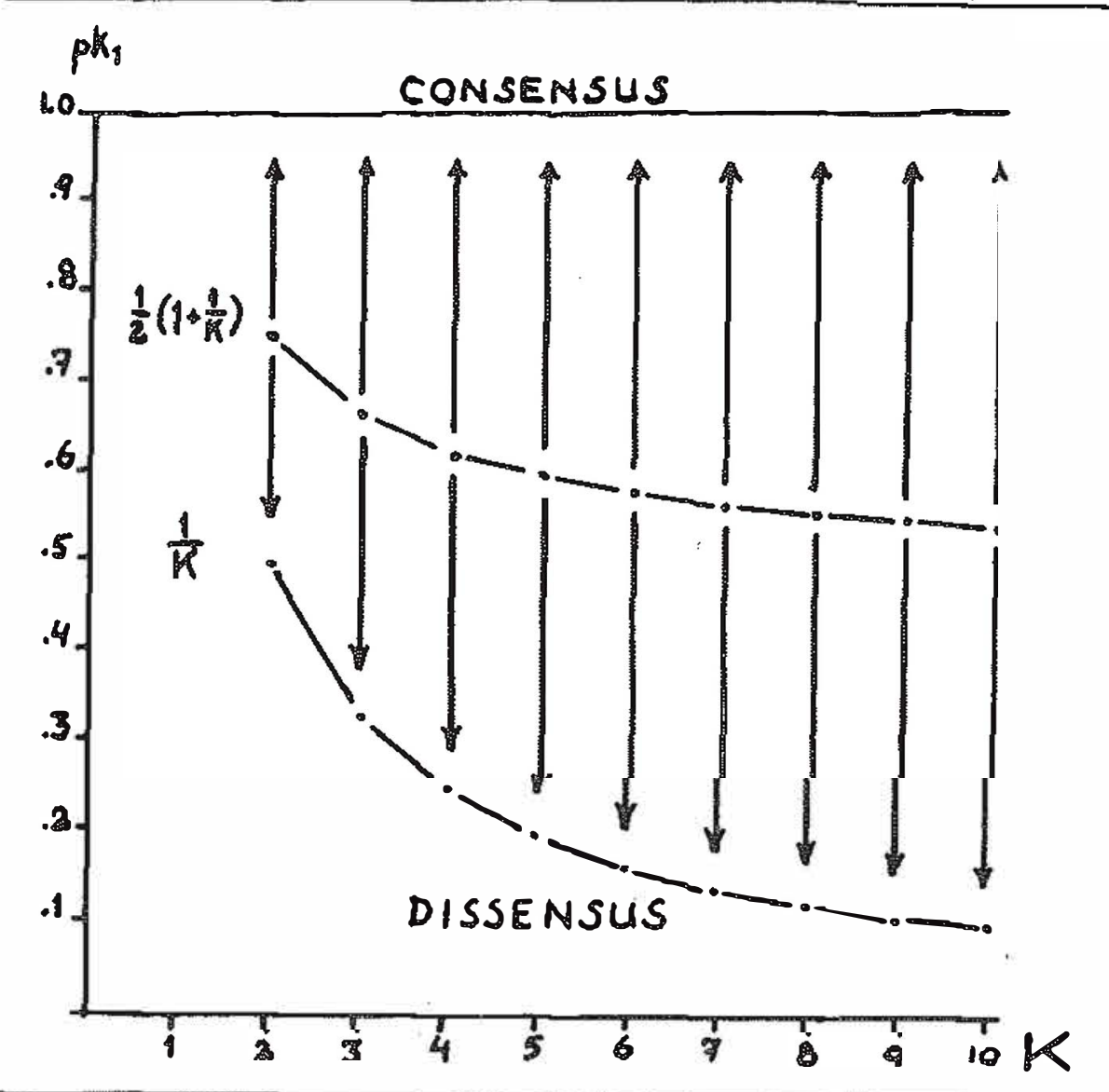

Figure 1

modal response signifies a norm. As an indicator of agreement, however, $\left(\mathrm{pk}_{1}-\mathrm{pk}_{2}\right)$ is less clear-cut than the modal proportion by itself, because $\left(\mathrm{pk}_{1}-\mathrm{pk}_{2}\right)$ can be quite large even when $p k_{1}$ is much less than $\mathrm{pk}_{1 \mathrm{rep}}$, provided that $\mathrm{pk}_{2}$ is small enough. Thus, the normative connotation of a modal proportion which is less than $\mathrm{pk}_{1 \text { rep }}$ depends not only on $\left(\mathrm{pk}_{1}-\mathrm{pk}_{2}\right)$, but also on the combined proportions of the first two categories, $\left(\mathrm{pk}_{1}+\mathrm{pk}_{2}\right)$. If these approach unity, then a large value for $\left(\mathrm{pk}_{1}-\mathrm{pk}_{2}\right)$ indicates that $\mathrm{k}_{1}$ has received much agreement. But if $\left(\mathrm{pk}_{1}+\mathrm{pk}_{2}\right)$ is relatively small, then the same large value for $\left(\mathrm{pk}_{1}-\mathrm{pk}_{2}\right)$ means that even the most frequent response was made by only a small proportion of the respondents, and that there is much disagreement among them. 
We can overcome this difficulty by taking $\left(\mathrm{pk}_{1}-\mathrm{pk}_{2}\right)$ and weighting it with $\left(p k_{1}+p k_{2}\right)$. In this manner we shall have obtained a measure which is sensitive to variations in $\mathrm{pk}_{1}$ as well as in $\mathrm{pk}_{2}$, and which therefore accurately reflects the relative prominence of the statistical mode. We have given this expression the symbol $\triangle^{2}$ because algebraically, it is the difference of squared proportions of the two largest response categories. It has a range of $(0,1) .^{5}$

$$
\Delta^{2}=\left(p k_{1}-p k_{2}\right) \cdot\left(p k_{1}+p k_{2}\right)=p k_{1}^{2}-p k_{2}^{2} .
$$

To establish the standard lower limit for $\Delta^{2}$, we start by replacing $\mathrm{pk}_{1}$ in formula 2 with $\mathrm{pk}_{1 \text { rep }}$, thereby making sure that a modal proportion which meets the criterion of $\mathrm{pk}_{\mathrm{irep}}$ will always be above the lower limit of $\Delta^{2}$.

$$
\Delta^{2}=[1 / 2(1+1 / K)]^{2}-\mathrm{pk}_{2}^{2}
$$

Now let us consider the distribution of $\mathrm{pk}_{2}$, this being the additional element that has to be taken into account. So long as $\mathrm{pk}_{1}$ is greater than $\mathrm{pk}_{1 \text { rep, }}$, the value of $\mathrm{pk}_{2}$ does not make much difference, since its range is in any case severely restricted by the magnitude of $\mathrm{pk}_{1}$. But when $\mathrm{pk}_{1}$ is less than $\mathrm{pk}_{1 \text { rep }}$ (and these are the cases with which we are now concerned), then $\mathrm{pk}_{2}$ can reach considerably higher values, and it is precisely these higher values of $\mathrm{pk}_{2}$ which reduce the relative prominence of $\mathrm{pk}_{1}$. The lower cutoff point for $\Delta^{2}$ should therefore incorporate an upper limit for $\mathrm{pk}_{2}$ :

For any value of $\mathrm{pk}_{\mathrm{frep}}$ there is a corresponding maximal value for $\mathrm{pk}_{2}$. This will occur when all proportions besides those in the first two categories are minimal but nonzero-that is to say, when the proportion in each of the remaining categories is $1 / \mathrm{N}$.

$$
\mathrm{pk}_{2 \max } \mid \mathrm{pk}_{\text {irep }}=1-1 / 2(\mathrm{I}+1 / \mathrm{K})-(\mathrm{K}-2) / \mathrm{N} \text {. }
$$

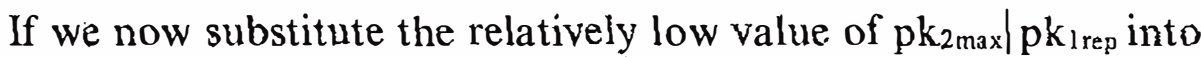
equation 3 , the result will be a $\Delta^{2}$ value for any $\mathrm{K}$ and $\mathrm{N}$ which, when applied to $\mathrm{pk}_{1}$ values that are less than $\mathrm{pk}_{1 \text { rep }}$, sets a minimal level of prominence for the modal category, based on the logic of 
$\mathrm{pk}_{\text {irep }}$, but one that is always lower than $\mathrm{pk}_{1_{\mathrm{rep}} \text {, }}$

$$
\begin{gathered}
\triangle_{\text {prom }}^{2}=\left(\mathrm{pk}_{1 \mathrm{rcp}}\right)^{2}-\left(\mathrm{pk}_{2 \mathrm{max}} \mid \mathrm{pk}_{1 \mathrm{rcp}}\right)^{2} \\
=[1 / 2(1+1 / \mathrm{k})]^{2}-[1-1 / 2(1+1 / \mathrm{K})-(\mathrm{K}-2) / \mathrm{N}]^{2}
\end{gathered}
$$

Any $\Delta^{2}$ value below this point will mean, in fact, that $\mathrm{pk}_{2}$ is so close to $\mathrm{pk}_{1}$ that the modal response is no longer sufficiently different from the next most frequent response to be called a social norm of that population (for minority norms, see below).

Now, when dealing with large populations or when $K=2$, the term $(\mathrm{K}-2) / \mathrm{N}$ in equation 5 tends to zero, and the whole formula cancels down to $\mathrm{I} / \mathrm{K}$. This convenient fact allows us to compute minimal $\mathrm{pk}_{1}$ values which will correspond to $\triangle_{\mathrm{prom}}^{2}$. We shall call this $\mathrm{pk}_{\mathrm{iprom}}$, and the argument is as follows.

Given $\triangle_{\text {prom }}^{2}, \mathrm{pk}_{1}$ can be minimal when $\mathrm{pk}_{2}$ is also minimal, because then we have the largest possible difference between $\mathrm{pk}_{1}$ and $\mathrm{pk}_{2}$. The minimal value for $\mathrm{pk}_{2}$ is $1 / \mathrm{N}$, and for a large $\mathrm{N}$ this approaches zero. For large populations, therefore,

$$
\begin{gathered}
\triangle_{\text {prom }}^{2}=p k_{1 \text { prom }}^{2}-0^{2}=1 / \mathrm{K} ; \text { or } \\
\mathrm{pk}_{1 \text { prom }}^{2}=1 / \mathrm{K} ; \text { or } \\
\mathrm{pk}_{\text {prom }}=\sqrt{1 / \mathrm{K} .}
\end{gathered}
$$

For smaller populations, we have computed the appropriate values for $\mathrm{pk}_{1 \mathrm{prom}}$ from formula 5 , and they are given in the Appendix. Results from samples can be tested for significance by computing a one-tailed lower confidence limit for the observed modal proportion at the desired fiducial level, and checking whether this is equal to or greater than $\sqrt{1 / \mathrm{K}}$.

In sum, then, when $\mathrm{pk}_{1}$ is less that $\mathrm{pk}_{1 \text { rep }}$ but greater than $\mathrm{pk}_{1 \text { prom, }}$ we shall call the modal response a prominent norm, because that is the distinguishing characteristic of such a mode. It is not large enough to be a representative norm, but it is still so prominent among all the other response categories that it definitely indicates a norm. 


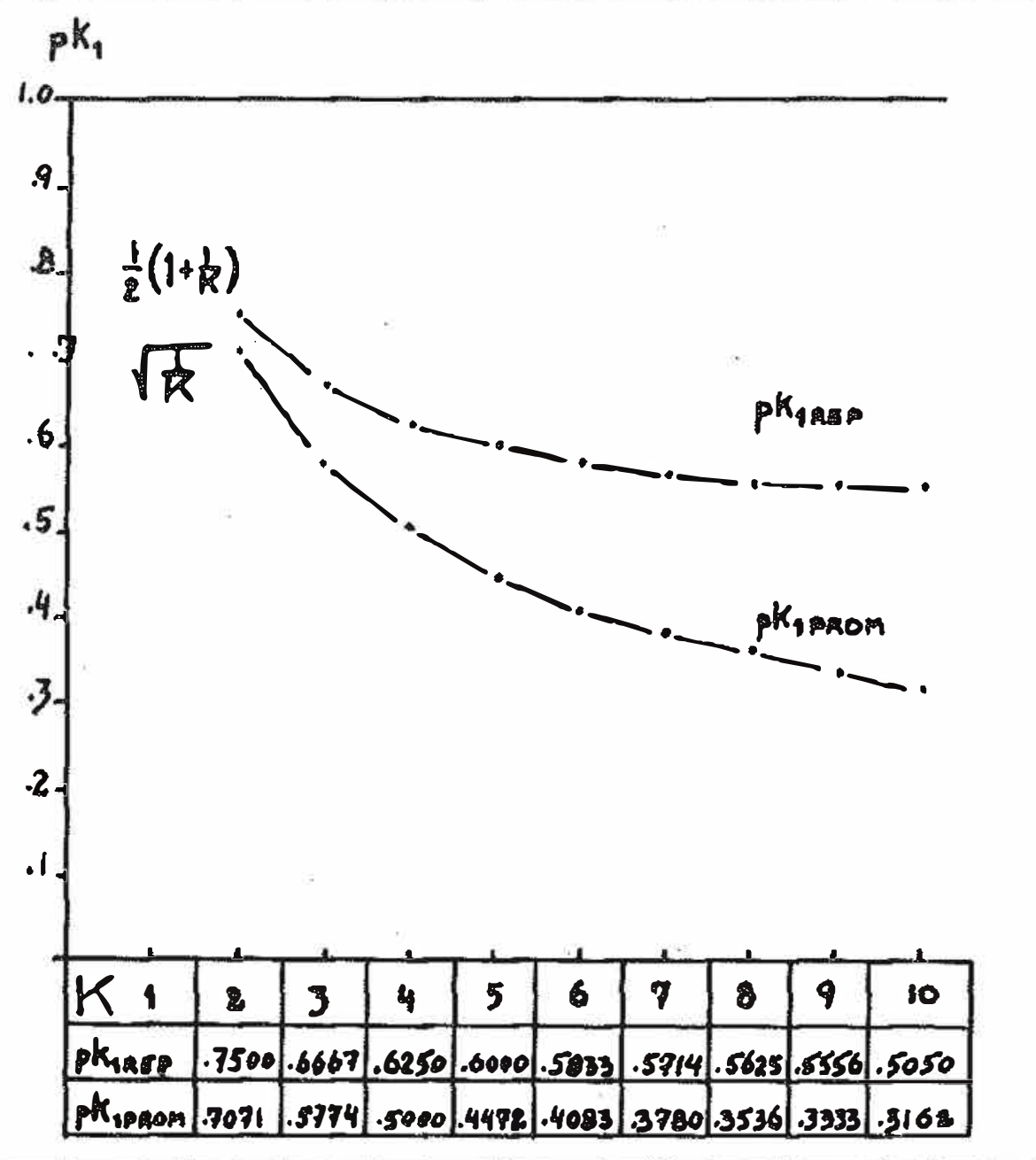

Figure 2

MINORITY NORMS

Having discovered a prominent norm does not permit us to conclude that we are dealing with an exclusive norm. Constellations may arise in which $\mathrm{pk}_{2}$ is still so large that, in sociological terms, we should consider the distribution bimodal. In fact, the more perplexing problems in the sociological analysis of normative systems, those which are most in need of quantitative criteria for consistent interpretation, are found where we suspect the existence of minority norms in a population. Of course, the frequency distribution itself, if it contains two or more peaks, can 
give us a rough indication of bimodality or multimodality. But to arrive at reliable and reproducible decisions, we need a standardized and convincing cutoff point to determine just when $\mathrm{pk}_{2}$ is large enough to be interpreted as a minority norm.

The procedure we propose is directly analogous to, and follows the same logic as, that used in determining $\mathrm{pk}_{\mathrm{i} \text { rep }}$. The upper limit of $\mathrm{pk}_{2}$ is, by definition, always just below .5 , because if $\mathrm{pk}_{2}=.5$, it is no longer the second largest proportion, but becomes equal to $\mathrm{pk}_{1}$. This is the situation in which we would be certain that the distribution is bimodal, and the closer $\mathrm{pk}_{2}$ is to .5 , the more grounds we have to say that there is a minority norm.

At the other extreme, we are certain that there is no minority norm when $\mathrm{pk}_{2}$ is at its minimum, namely $1 / \mathrm{N}$. The midway point, then, between $\mathrm{pk}_{2}=1 / \mathrm{N}$ and $\mathrm{pk}_{2}=.5$, namely

$$
1 / \mathrm{N}+[.5-(1 / \mathrm{N})] / 2=.25+1 / 2 \mathrm{~N},
$$

is the point where we can say that any $\mathrm{pk}_{2}$ above it indicates a distribution which is nearer to bimodality than to unimodality, and therefore represents a minority norm. For large populations, $1 / 2 \mathrm{~N}$ tends to zero, so that $\mathrm{pk}_{2}=.25$ may be taken as a convenient approximate cutoff point for a minority norm.

Note that this cutoff point is based on the theoretical distribution of $\mathrm{pk}_{2}$ and can therefore be logically justified only to interpret $\mathrm{pk}_{2}$. A pk $\mathrm{pk}_{3}$ as high as 25 can occur only when $\mathrm{pk}_{2}$ is more than .25, and then $\mathrm{pk}_{1}$ is always less than $\mathrm{pk}_{1 \mathrm{prom}}$. In such cases, then, there simply is no norm.

On the other hand, a $\mathrm{pk}_{1}$ as low as .25 can be $\mathrm{pk}_{1 \mathrm{prom}}$ only when two conditions are met: $\mathrm{pk}_{2}$ must be at a minimum $(1 / \mathrm{N})$, and at the same time there must be at least 16 response categories. In those special cases, then, $\mathrm{pk}_{1}$ can be no more than .25 and still indicate a prominent norm. For all practical purposes, however, when $\mathrm{pk}_{1}$ is as low as that, it means that there is widespread disagreement. To be consistent in our terminology, however, having called a proportion of $.25+1 / \mathrm{N}$ a norm (albeit a minority norm) when it occurs in $\mathrm{pk}_{2}$, we should also call it a norm of some sort when it is found in a pk $\mathrm{k}_{1}$. Obviously, it cannot be a minority norm, but since it represents the plurality of responses, we shall call it a plurality norm. 
A special problem arises when the response categories are not nominally different from one another but are arranged in some order on one dimension. In such cases it makes a difference whether or not $k_{1}$ is contiguous to $k_{2}$. If the two largest categories are not contiguous, then the logic of $\mathrm{pk}_{1 \mathrm{prom}}$ and minority norms holds just as if we were dealing with nominal categories. However, if $\mathrm{k}_{1}$ and $\mathrm{k}_{2}$ are contiguous and $\mathrm{pk}_{2}>.25+(1 / 2 \mathrm{~N})$, then it is probably more correct to interpret $\mathrm{k}_{2}$ as a tendency toward the modal category rather than as a distinct and different minority norm.

Sometimes, when $k_{1}$ is contiguous to $k_{2}$, the researcher may want to collapse the two largest categories, thereby obtaining a prominent or even a representative norm. While this is possible, it should never be done as a mere matter of computational convenience, since the implication of such a decision is that there was something wrong with the original formulation of the response categories. The collapsing of adjacent categories should therefore always be justified on conceptual grounds. Only then will the interpretation be valid.

Not only response categories but also questionnaire items may be conceptually contiguous. In principle, any suitably worded question could yield a norm as here defined. That is as it should be, since we do not want the procedure to rule out any empirical possibility. But questions with contiguous or overlapping behavioral referents could conceivably yield different norms for much the same behavior. ${ }^{7}$ The seriousness of this problem depends on what the researcher is trying to do: to identify the "true" norm or to explain behavior in terms of normative expectations.

In studies attempting to describe social reality as precisely as possible, contiguous items are an advantage because they are the means whereby normative system can be accurately presented in all its complexity. This, presumably, is Schuman and Duncan's (1974: 234-236) intention in their use of the phrase "meaningful variations in question marginals." If the $\mathrm{pk}_{\mathrm{I}}$ values for the contiguous items are different from one another, the item with the 
largest $\mathrm{pk}_{1}$ will be the closest description of the normatively regulated behavior, and $k_{1}$ of that item will reflect the norm. But if the contiguous items yield equally prominent modes, it simply means that the norm reflected in the one mede is the same as that reflected in the others, regardless of variations in wording, and nothing is lost except a few redundant questions.

However, if we want to find out whether a given type of behavior is socially required, permitted, tolerated, or proscribed, then contiguity between items should be avoided and the stimulus made as una mbiguous as possible. Repeated pretesting is one way of obtaining the necessary iterations to eliminate conceptual contiguity between questionnaire items and to identify the single most fitting description of the behavior to be studied. In our own research on littering and traffic violations, we have used visual stimuli (movies, television) to reduce variation on this score. Whatever the technique, great care must always be taken when constructing questionnaire items to measure social norms.

\section{$S U M M A R Y$}

In response to the repeatedly voiced need for quantitative techniques to measure social norms, we are proposing a series of standard criteria to facilitate the consistent sociological interpretation of modal frequencies. The procedure may be summarized as follows:

(1) Compute $\mathrm{pk}_{1}$. If $\mathrm{pk}_{2}>1 / 2[1+(1 / \mathrm{K})]$, the modal category indicates a representative norm.

(2) If $1 / 2[1+(1 / K)]>p k_{1}>\sqrt{1 / K}$, then the modal category signifies a prominent norm.

(3) If $\sqrt{1 / K}>\mathrm{pk}_{1}>.25+(1 / 2 \mathrm{~N})$, there is no prominent norm, but the modal category may be called a plurality norm.

(4) In any case, even if there is a representative norm or a prominent norm, but especially if there is none, check for bimodality. If $\mathrm{pk}_{2}>.25+(1 / 2 \mathrm{~N})$, then $\mathrm{k}_{2}$ represents a minority norm, provided that it is not contiguous with $\mathrm{k}_{1}$. If $\mathrm{k}_{1}$ and $\mathrm{k}_{2}$ are contiguous, $\mathrm{pk}_{2}>.25+(1 / 2 \mathrm{~N})$ indicates a tendency toward the modal category and should be so reported. 


\section{EXAMPLE I}

In a study of college students' value patterns, Hoge (1974) compared students at Dartmouth College with those at Michigan University in the 1950s and 1960s. One of the items to which he asked respondents to react was the following statement: "People who talk about politics without knowing what they are talking about should be kept quiet."

The modal response in each case was "disagree." But which of these modes signifies social norms? The $80 \%$ of the Dartmouth students who disagreed in 1968 seem to answer the questions clearly enough, but what about the $72 \%$ of the Michigan students in 1969? Still more uncertain are the modal responses found in 1952. With our proposed criteria, the interpretation is clear and unequivocal.

In 1952, opinions were divided among the Dartmouth students. There was a plurality norm disagreeing with the statement but also a significant minority norm agreeing with it. Michigan students of the same year, on the other hand, had a highly significant prominent norm negating the statement, while the $27 \%$ that agreed are not enough to constitute a minority norm. By 1968-1969 the difference in normative structure between the two universities had narrowed, although the raw percentage difference in modal responses is larger (!). In both places there was a significant representative norm negating the statement, although in Michigan it is not as clear as at Dartmouth.

\section{EXAMPLE 2}

Our second example has been chosen to demonstrate the case of contiguity. It is taken from a study by Mäkelä (1967), in which he compared the public sense of justice with legal practice in Finland. On a scale ranging from "acquittal" $(0)$ to "more than one year of unconditional imprisonment" (5), the punitive demands made by the public were compared to the sentences pronounced by judges. Table 2 is based on data from Mäkelä's original Table 8. 
TABLE 1

Responses and Interpretation of Item 3 on Social Constraints

(from Table 6 in Hoge, 1971)

$\mathrm{K}=3 ; \quad \mathrm{pk}_{\text {lrep }}=.6667 ; \quad \mathrm{pk}_{1 \mathrm{prom}}=.5774 ; \quad \mathrm{pk}_{2 \mathrm{~min}}=\underline{.2500}$

\begin{tabular}{|c|c|c|c|c|}
\hline & $\begin{array}{c}\text { Dartmouth } \\
1952 \\
(n=364)\end{array}$ & $\begin{array}{c}\text { Michigan } \\
1952 \\
(n=398)\end{array}$ & $\begin{array}{c}\text { Dartmouth } \\
1968 \\
(n=368)\end{array}$ & $\begin{array}{c}\text { Michigan } \\
1969 \\
(n=387)\end{array}$ \\
\hline AGREE & .31 & .27 & .14 & .20 \\
\hline DISAGREE & .61 & .67 & .80 & .72 \\
\hline UNCERTAIN & .07 & .06 & .06 & .09 \\
\hline $\begin{array}{l}\text { Lorver Confidence } \\
\text { linits }(.01)\end{array}$ & & & & \\
\hline $\mathrm{pk}_{1}-2.33 \sqrt{\mathrm{pq} / \mathrm{n}}$ & .5504 & .6151 & .7514 & .6668 \\
\hline$p k_{2}-2.33 \sqrt{p q / n}$ & .2535 & .2182 & m & - \\
\hline Interpretation & $\begin{array}{l}\text { Plurality } \\
\text { norm; } \\
\quad+ \\
\text { Minority } \\
\text { norm }\end{array}$ & $\begin{array}{l}\text { Prominent } \\
\text { norm; } \\
\text { no } \\
\text { Minørity } \\
\text { norm }\end{array}$ & $\begin{array}{l}\text { Represent. } \\
\text { norm; } \\
\text { no } \\
\text { Minority } \\
\text { norm }\end{array}$ & $\begin{array}{l}\text { Represent } \\
\text { norm; } \\
\text { no } \\
\text { Minority } \\
\text { norm }\end{array}$ \\
\hline
\end{tabular}

In order to show the degree to which the public agrees with or differs from the judges Mäkelä computed the means for the public and the judges, respectively, and subtracted the one from the other. He reports that in the case of drunkenness, the public's mean is 0.2 (degrees? levels?) more severe than the judges', and in the case of abortion the difference is 0.1 , with the public's mean being slightly more severe.

Using our suggested criteria, we find that there is a significant prominent norm among members of the public $(45 \%)$ that drunkenness should be punished with a small fine. While a minority would acquit (27\%), they are not enough to make a significant minority norm. There is, moreover, a second minority of $23 \%$ who would give a substantial fine. For judges, however, 
TABLE 2

Punitive Demands Made by the Public and Sentences

Pronounced by Judges for Drunkenness and Abortion: Responses and Interpretation

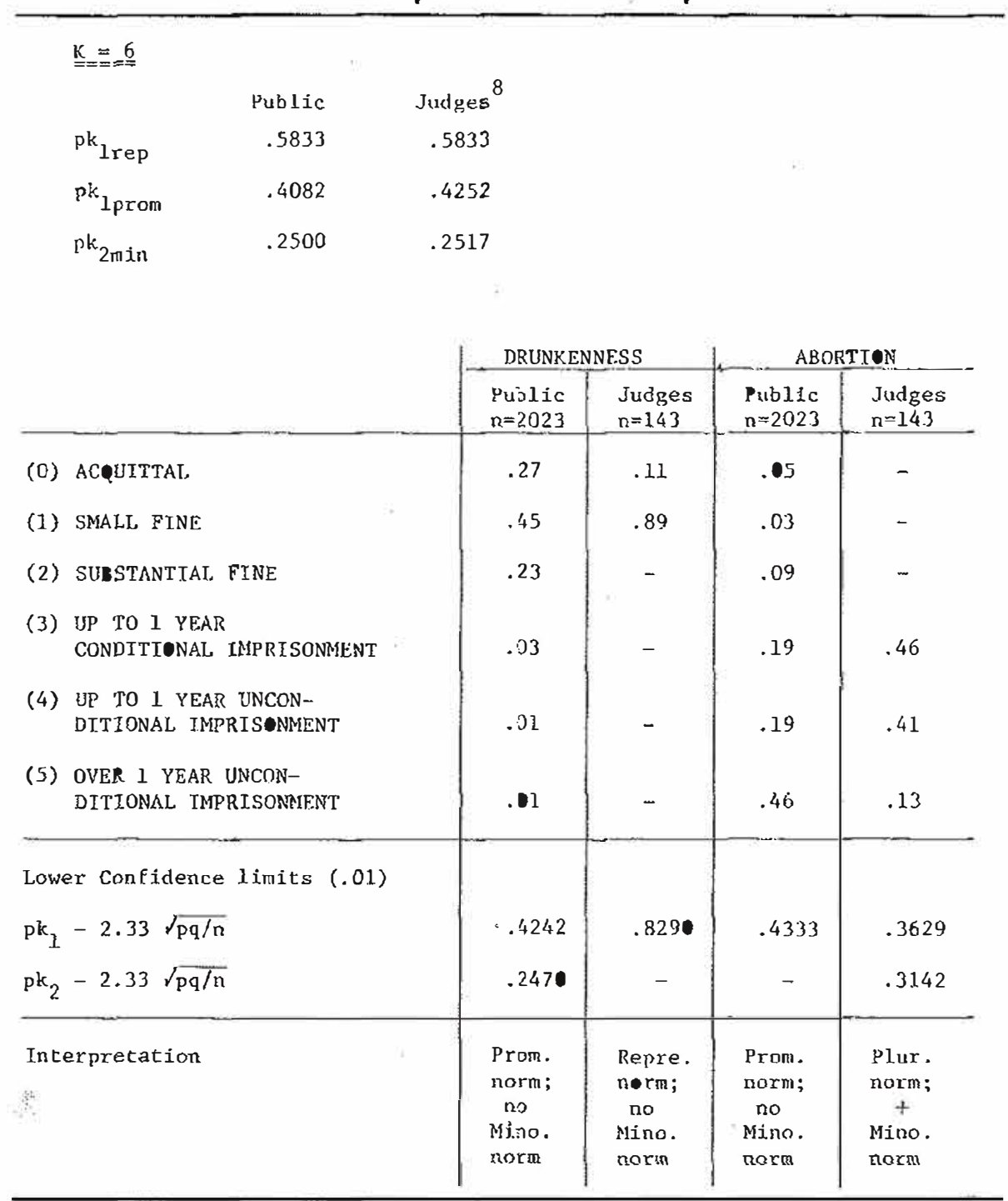

the small fine is a representative norm (89\%), despite the $11 \%$ who did acquit. Our conclusion, therefore, is not that members of the public are more severe than the judges, but that they are more divided in their opinions.

For abortion, there is a prominent norm among the public (46\%) demanding the maximum sentence. It is true that the others 
in the sample were more lenient, but they don't coalesce into a minority norm. Judges are much more lenient toward this offense. The plurality norm among them is to give up to one year conditional imprisonment (probation). Although the modal category has the same proportion (46\%) as that of the public, it is not enough to make a significant prominent norm because the sample is so much smaller. There is also a significant minority norm (41\%) giving up to one year unconditional imprisonment, but the two categories are contiguous and the tendency is toward the more lenient norm. Thus, our conclusion is again different from Mäkeläs. The difference between the public and the judges is much greater with regard to abortion than to drunkenness.

\section{NOTES}

1. Some writers have defined norms by the frequency with which a behavior occurs (for an example, see Hill, 1974). This seems to us unacceptable, conceptually as well as methodologically.

2. Hofstaetter (1963: 132n) has suggested a formula for computing majority opinions: $M$ $=\left(p_{+}-p_{-}\right) \cdot\left(100-p_{*}\right) / 100$, where $p_{+}$and $p_{-}$signify percentages agreeing and disagreeing, respectively, and $p_{0}$ the percentage undecided. However, he does not suggest any criterion for deciding when a majority is large enough to indicate a norm.

3. In the absence of evidence pointing to alternative functions, we have followed the principle of Occam's razor and made what seemed the simplest assumption.

4. This kind of procedure, though common enough, is not really appropriate by the strict logic of inferential statistics. It treats $\mathrm{pk}_{1}$ as if it were based on a binomial distribution, whereas in fact (except when $\mathrm{K}=2$ ) it is based on a multinomial distribution (see Guttman, 1977: problem 1). Thus, the confidence interval tends to be too narrow, leading us to the possible error of identifying sample mode as a representative norm when, in fact, the population mode is below $\mathrm{pk}_{\mathrm{ircp}}$. However, since the exact calculation of the distribution of $\mathrm{pk}_{1}$ for different values of $\mathrm{pk}_{2}, \mathrm{pk}_{3} \ldots \mathrm{pk}_{\mathrm{n}}$ is a complicated and timeconsuming matter, we suggest, a rough-and-ready provisional procedure until appropriate tables are available, compensating for the underestimation by raising the fiducial level from the customary .05 to .01 .

5. Bechofer et al. (1959) have suggested the ratio $\mathrm{pk}_{1} / \mathrm{pk}_{2}$ for a similar problem. For two reasons, this seems less appropriate than $\triangle^{2}$ to our purposes: (1) the ratio $\mathrm{pk}_{1} / \mathrm{pk}_{2}$, like $\left(\mathrm{pk}_{1}-\mathrm{pk}_{2}\right)$, is not sufficiently sensitive to $\mathrm{pk}_{1}$, so that the same large (or small) values can result from widely different modal responses; (2) unlike $\Delta^{2}$, which has a permanent and heuristically convenient reference point in $\Delta_{\max }^{2}=1.00, \mathrm{pk}_{\mathrm{i}} / \mathrm{pk}_{2 \max }$ varies with the total number of responses.

6. See note 4 .

7. We are indebted to the editors for pointing out to us this difficulty.

8. This case illustrates the need for $p k_{1 p r o m}$ values for small populations. Since the total population of judges in Finland was reported as approximately $300, \mathrm{pk}_{\text {iprom }}=.4252$ (see Appendix), and not $\sqrt{\mathrm{l} / \mathrm{K}}=.4082$. 


\section{REFERENCES}

BECHOFER, R. E., S. ELMAGHABRY, and N. MORSE (1959) "A single-sample multiple-decision procedure for selecting the mutinomial cvent which has the highest probability." Annals of Mathematical Statistics 30: 102-119.

BLALOCK, H. M., Jr. (1960) Social Statistics. New York: McGraw-Hill.

GIBBS, J. P. (1968) "The study of norms," pp. 208-212 in D. L. Silts (cds.) International Encyclopedia of the Social Sciences, Volume 11. New York Macmillan.

- (1965) "Norms: the problem of definition and classification." Amer. J. of Soci oingy 70: $586-594$.

GUTTMAN, L. (1977) "What is not what in statistics." Statistician, 26, 2: 81-107.

HAWKES, R. K. (1975) "Norms, deviance and social control: a mathematical elaboration of concepts." Amer. J. of Sociology 80, 4: 886-908.

HENDRIX, L. (1976) "Comment on Hawkes's 'Norms, deviance and social control,"” Amer. J. of Sociology 81, 6: 1494-1498.

HILL, S. (1974) "Norms, groups and power: the sociology of the workplace." Industrial Relations 12: 213-235.

HOFSTAETTER, P. R. (1963) Einfuehrung in die Sozialpsychologie. Stuttgart: Alfred Kroener Verlag.

HOGE, D. R. (1974) "College students' value patterns in the 1950's and 1960's. "Sociology of Education 44, 2: 170-197.

KOLB, W. L. (1964) "Norm," definition A, c in J. Gould and W. L. Kolb (eds.) A Dictionary of the Social Sciences. New York: Free Press.

LABOVITZ, S. and R. H AGEDORN (1973) "Measuring social norms." Pacific Soc. Rev. 16, 3: 283-303.

MÄKELÄ, K. (1967) "Public sense of justice and judicial practice." Acta Sociologica 10: 42-67.

MORRIS, R. T. (1956) "A typology of norms." Amer. Soc. Rev. 21: 610-613.

MUELLER, J. H. and K. F. SCHUESSLER (1961) Statistical Reasoning in Sociology. Boston: Houghton Mifflin.

ROSSI, P. H., E. WAITE, C. E. BOSE, and R. E. BERK (1974) "The seriousness of crimes: normative structure and individual differences." Amer. Soc. Rev. 39: 224-237.

SCHUMAN, H. and O. D. DUNCAN (1974) "Questions about attitude survey questions." pp. 232-251 in Sociological Methodology 1973-1974. San Francisco: Jossey-Bass.

SUMNER, W. G. (1906) Folkways: A Study of The Sociological Importance of Usages, Manners, Customs, Mores, and Morals. New York: Dover.

TURK, H. (1965) "An inquiry into the undersocialized conception of man. "Secial Forces 43 (May): 518-521.

WILLIAMS, R. M., Jr. (1968) "The concept of norms," pp. 204-208 in D. L. Sills (ed.) International Encyclopedia of the Social Sciences Volume II. New York: Macmillan.

—— (1951) American Society: A Sociological Interpretation. New York: Knopf. 
APPENDIX

Some Useful Minimal Values of $\mathbf{p k}_{1 \text { prom }}$ for Small Populations (decimal point omitted)

\begin{tabular}{|c|c|c|c|c|c|c|c|c|c|}
\hline$k=$ & 2 & 3 & 4 & 5 & 6 & 7 & 8 & 9 & 10 \\
\hline$N$ & & : & & & & & & & \\
\hline 30 & 7303 & 6231 & 5736 & 5507 & 5415 & 5396 & 5416 & 5453 & 5498 \\
\hline 40 & 7246 & 6124 & 5568 & 5286 & 5147 & 5092 & 5086 & 5110 & 5148 \\
\hline So & 7211 & 6058 & 5463 & 5142 & 4968 & 4884 & 4854 & 4879 & 4883 \\
\hline 100 & 7141 & 5921 & 5240 & 4828 & 4564 & 4395 & 4288 & 4225 & 4190 \\
\hline 200 & 7106 & 5851 & 5192 & 4776 & 4509 & 4338 & 4230 & 4165 & 4130 \\
\hline 300 & 7095 & 5825 & 5084 & 4590 & 4252 & 4001 & 381.3 & 3677 & 3558 \\
\hline 400 & 7089 & 5814 & 4894 & 4565 & 4212 & 3948 & 3747 & 3592 & 3466 \\
\hline 50 & 7085 & 5808 & 5050 & 4548 & 4186 & 3915 & 3705 & 3543 & 3407 \\
\hline 1000 & 7071 & 5794 & 5025 & 4510 & 4098 & 3848 & 3622 & 3441 & 3288 \\
\hline$\omega$ & 7071 & 5744 & 5000 & 4472 & 4087 & 3782 & 3536 & 3332 & 3162 \\
\hline & \multicolumn{2}{|c|}{$\mathrm{pk}_{1 \mathrm{prom}}=$} & {$[1 / 1$} & $\left.\frac{1}{\mathrm{~K}}\right\rangle \mathrm{J}^{2}$ & \multicolumn{4}{|c|}{$-\left[1-{ }_{2}\left(1+\frac{1}{K}\right)-\frac{(K-2)}{N}\right]+\frac{1}{N}$} & \\
\hline
\end{tabular}

Chanoch Jacobsen is Senior Lecturer in Applied Sociologl at the Technion, Israel Institute of Technolog.?. His research revolves around various manifestations of instilutionalized evasions of institutional rules, such as traffic violations, littering, and unauhorized strikes. Recent publications inchude "permissiveness and Norm Evasions: Definitions, Relationships, and Implications," in Sociology (Ma.' 1979), and (with Tamar Avi-Itzhak) "Identifying the Factors which Influence the Care of Public Places," in Urban Ecology $(3,1978)$.

Theo J.M, van der Voordt is Research Associate with the Department of Architecture at the Delft University of Technology. He has written some articles about the image of the inner cilies of Delfi, Antwerp, and Brussels, and is now studing how the development of a network of informal sociai control relates to environmental characteristics. A publication. "Subwa!s and Fe'elings of Anxiet!'," coauthored with Herman van Wegen. will be appearing in the Delfi Universit!" Progress. 